\title{
THE REGIONAL DEVELOPMENT OF THE RURAL AREAS IN BULGARIA AND THE SUPPORT OF THE EUROPEAN UNION
}

\author{
Kamen Petrov ${ }^{1}$
}

Received 27 October 2020, Revised 18 December 2020, Accepted 20 January 2021

\begin{abstract}
This exhibition is dedicated to the regional problems of rural areas in Bulgaria. The European dimensions of the territorial development of rural areas and their role for the socio-economic development of the population are successively considered. Gradually, the focus shifts to Bulgaria, addressing the main challenges facing rural areas. The territorial problems in front of the settlements, the emerging demographic problems accompanied by internal migrations, are presented. An analysis was made about the problems with employment, the deteriorated social infrastructure, and other problems, which show the real picture of the rural areas in Bulgaria. The overall analysis reveals the needs of rural areas and the state of the population in it. Recommendations are proposed for the implementation of targeted policies for regional rural development.
\end{abstract}

Key words: regional processes, rural areas, development, local problems, villages, remote areas, structure

\section{Introduction}

In the various member states of the Council of Europe, the rural population still makes up a significant part of the population. A strong rural development policy is needed to prevent unwanted migration flows. The aim of this policy is to diversify the employment structures in rural areas and to establish a new partnership between the village and the city. In 2018, in EU, $39.3 \%$ of the population lived in the cities, $31.6 \%$ lived in towns and suburbs, and $29.1 \%$ lived in rural areas. The aim of this publication is to provide guidelines on the social aspects of general rural development planning. In this respect, it would be good to develop rural areas economically. In the new century, they have created conditions for the development of innovations, which will help the regional economic development of rural areas. Undoubtedly, the processing industry of agricultural products, the development of rural tourism, ecological productions and the private initiative to improve the quality of life can be promoted in a new way. It is necessary to strengthen the spatial planning policy in order to maintain a balance between the many dynamic processes that affect rural areas (diversification of employment, changes in agricultural production, afforestation, tourism, nature protection). In most European

\footnotetext{
${ }^{1}$ Assoc. Prof. Dr. Kamen Petrov, Department "Regional Development", Faculty "Management and Administration", University of National and World Economy - Sofia, Bulgaria ORCD 0000-0002-6295-0664, petrovkamen@abv.bg, petrovk@abv.bg.
} 
countries, the condition of settlements in mountainous areas is deteriorating. In practice, rural areas in these areas represent an exceptional potential for Europe and perform numerous environmental, economic, social, cultural and agricultural functions. The spatial planning must pay special attention to the protection and development of rural areas in mountainous and semimountainous areas. Almost all countries with mountainous or hilly regions in EU have some kind of implicit or explicit 'mountain policy' or a mountain approach for certain issues. However, there are significant differences from country to country. These are principally countries with middle mountains and/or acceding/candidate countries. The most frequent sector to which mountain - focused policies are addressed is agriculture (17 countries).

Tab 1. Criteria for definition of mountain area in EU Member States. Sources: National reports; European Observatory of Mountain Forests

\begin{tabular}{|c|c|c|}
\hline Member State & Minimum elevation & Other criteria \\
\hline Austria & $700 \mathrm{~m}$ also above & $500 \mathrm{~m}$ if slope $>20 \%$ \\
\hline Germany & $700 \mathrm{~m}$ & climatic difficulties \\
\hline Greece & $800 \mathrm{~m}$ & $\begin{array}{l}\text { also } 600 \mathrm{~m} \text { if slope }>16 \% \text {; } \\
\text { below } 600 \mathrm{~m} \text { if slope }>20 \%\end{array}$ \\
\hline Italy & $600 \mathrm{~m}$ & altitudinal difference $>600 \mathrm{~m}$ \\
\hline France & $\begin{array}{l}700 \mathrm{~m} \text { (Generally) } \\
600 \mathrm{~m} \text { (Vosges) } \\
800 \mathrm{~m} \text { (Mediterranean) }\end{array}$ & slope $>20 \%$ over $>80 \%$ of area \\
\hline Spain & $1000 \mathrm{~m}$ & slope $>20 \%$ elevation gain $400 \mathrm{~m}$ \\
\hline Bulgaria & $600 \mathrm{~m}$ & $\begin{array}{l}\text { also }>200 \mathrm{~m} \text { altitudinal difference } / \mathrm{km}^{2} \\
\text { or slope }>12^{\circ}\end{array}$ \\
\hline Slovakia & $600 \mathrm{~m}$ & $\begin{array}{l}\text { also above } 500 \mathrm{~m} \text { on slopes }>7^{\circ} \\
\text { or average slope }>12^{\circ}\end{array}$ \\
\hline Romania & $600 \mathrm{~m}$ & also on slopes $>20^{\circ}$ \\
\hline Slovenia & $700 \mathrm{~m}$ & $\begin{array}{l}\text { also above } 500 \mathrm{~m} \text { if more than half the farmland is } \\
\text { on slopes of }>15 \% \text {; or slope }>20 \%\end{array}$ \\
\hline
\end{tabular}

In most European countries, implemented 'mountain' policies are mainly implicit: effectively, they are mainly sectoral policies with specific adaptations. From the perspective of many public and private actors, they are also often essentially equivalent to rural or regional policies. Agriculture is a crucial sector for mountain economies and land uses and for safeguarding scattered human settlements in mountain areas, but it is rarely the principal activity. Bringing to the fore, the problem of rural areas must show that there are significant areas in the European Union with regional disparities. By bringing regional development policy to the forefront, we can show the model of rural development in Bulgaria. Who are the representatives of regional business and public authorities involved in the planning and programming of rural policies. From a regional point of view, a large part of the territory of the European Union has rural areas that need to implement effective regional policies. Typical rural areas have a low population density and small settlements. Agricultural areas are commonly rural, as are other types of areas such as forests. Different countries have varying definitions of rural for statistical and administrative purposes. In this regard, let's assume that the rural area includes a territory or open plot of land, which has few homes with less building or other buildings, as well as not many people. The population density in rural areas is considered to be very low. 


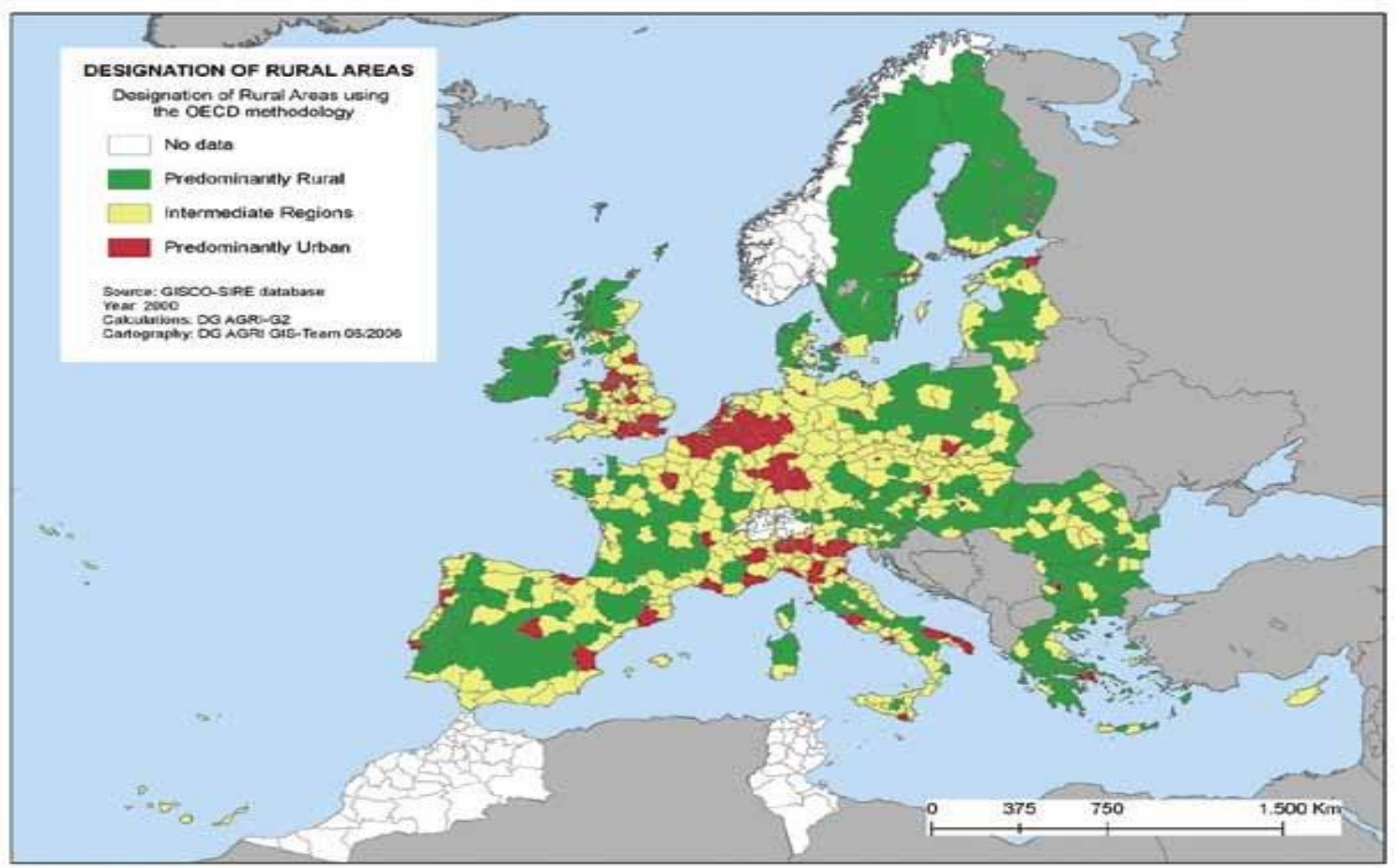

Fig 1. Rural areas in European Union countries. Sources: EU, Eurostat

\section{Structuring and management of rural areas in Bulgaria}

Rural areas are areas that are not urbanized. They have a low population density and usually a large part of the land is occupied by agriculture. In most parts of the world, rural areas are declining, a phenomenon that has been observed since the 19th century or so, both in terms of the territory they occupy and in terms of the share of the population living in them. Urbanization is increasingly invading rural lands while disrupting them, and thanks to agricultural mechanization, it has greatly reduced the number of workers needed to cultivate the land, while alternative employment is usually easier to obtain in cities. The Rural Development Program (RDP) 2007-2013 in Bulgaria defines as rural areas the municipalities in which the population does not exceed 30,000 people. According to this criterion of the RDP, 232 out of a total of 265 municipalities in Bulgaria are classified as rural. Rural areas occupy $81.4 \%$ of the country's territory. The largest area of rural municipalities is the South-Central region, and the smallest is the North-Central. The highest relative share of rural areas in the total area of the region is the Northeast region (88.4\%), and the lowest is North-Central (73.6\%). The current definition of rural areas has given rise to a number of discussions among mid-stakeholders during the implementation of the RDP. When it comes to economic development and financial stability of rural areas, the macro-environment in which they operate should be considered. The influence of the macroenvironment is essential for providing conditions for economic activity. The increase in value added by the economy of municipalities is the result of growth in consumption and income and has a favorable effect on economic and financial stability (Bachev et al., 2017). Stable and predictable macroeconomic environment is a key factor in the planning and implementation of the set goals of the business and for the development of the economic activity in a national one and regional aspect. The definition of the territorial scope of rural areas for the forthcoming programming period 2021-2027 is caused by the objectives of European policies for agricultural and rural development (CAP) and cohesion (Cohesion Policy) and the focus of certain interventions only in these areas. The definition of what is rural is rooted in a sense of place. Rural statistics describe conditions in rural places. The domain of rural statistics includes farm and non-farm households. Rural statistics are thus territorial statistics, in contrast to sectoral statistics that focus on single activities in rural areas, such as agriculture or forestry or education. The view of rural areas is comprehensive, including social, economic, and environmental aspects of life in those places (Vidal C et al., 2001). The situation with regard to road infrastructure has deteriorated sharply, mainly due to very limited investment in their 
renewal. The roads between the settlements and inside them are largely depreciated and do not meet modern standards. Rural municipalities are responsible for the management of over 16 thousand $\mathrm{km}$. municipal roads, as well as on the streets in settlements in rural areas. A specific problem is the poor condition of the third and fourth class roads. There is a total of 1,479 schools in rural municipalities, of which 174 are vocational high schools. The school system in rural municipalities is relatively well developed. However, there is a tendency to withdraw children from the education system, especially in minority groups. Like other public buildings, education needs significant investment to improve their general condition and equipment. A total of 26,122 teachers work in educational institutions in the rural areas of the country - 18 teachers on average per institution (compared to 32 on average for the country).

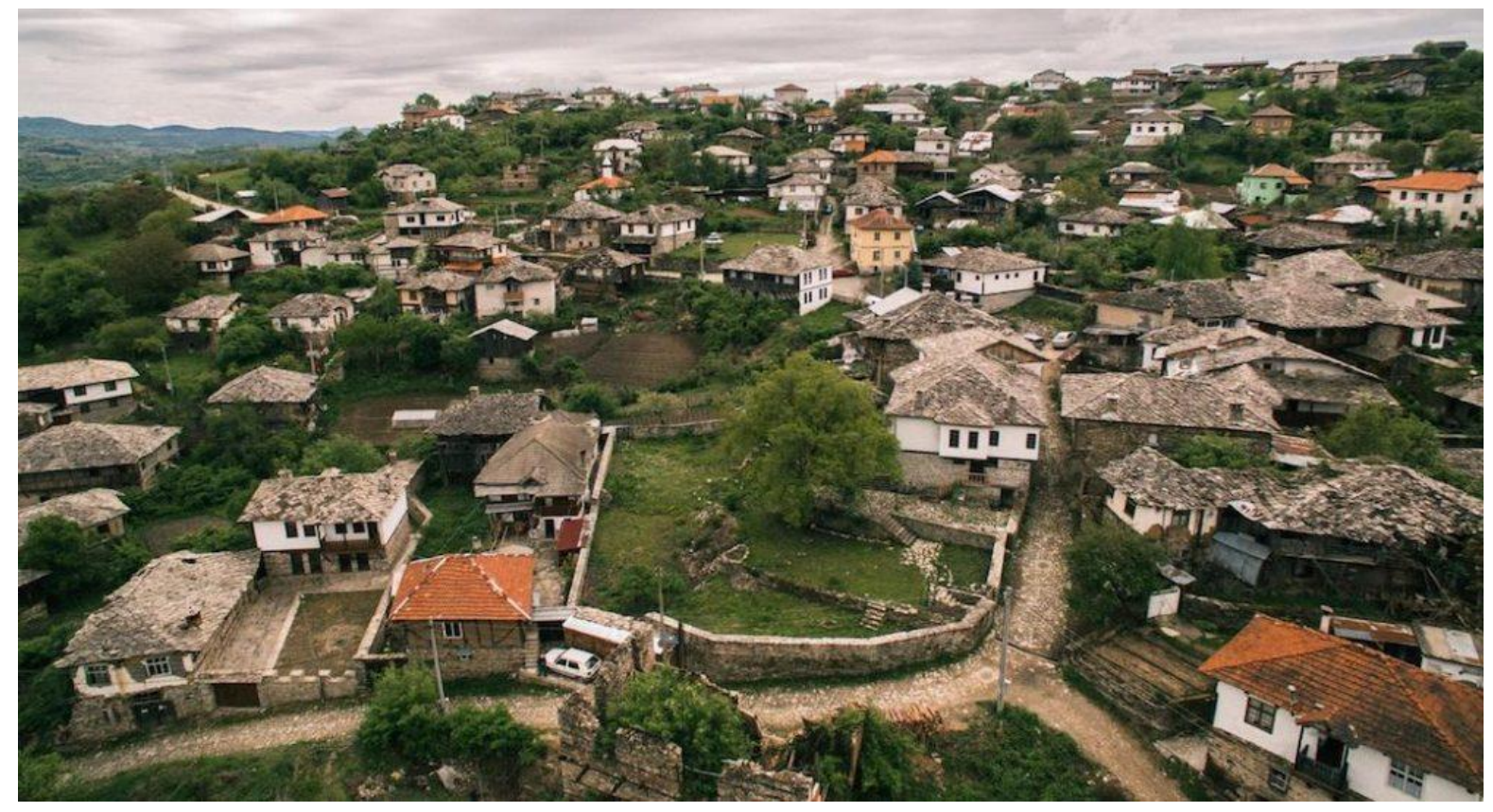

Fig 2. View from a Bulgarian village - Dolen village, Mountain Rhodopi. Source: Global Grasshoppe

The approach to the development of the settlement and especially the inhabited territories outside the cities can be defined as rural areas including municipalities (LAU 1), in which there is no settlement with a population of over 30,000 people. The scope of this definition is 232 municipalities on the territory of Bulgaria, including two newly formed municipalities - Sopot (since 2003) and Sarnitsa (since 2015). Rural areas are the municipalities on whose territory there is no city with a population of over 30,000 people and the population density is less than 150 inhabitants per square kilometer. The influence of the macro environment is so important for the regional development of the country. In the Bulgarian version, apart from the economic indicators, is the demographic picture in the rural areas (Kopeva D et al., 2010). Assuming that through programs and policies, we will improve rural areas, how this will affect the population. This means that at the rural level, a predictable macroeconomic environment must be sought. The macro environment can be a key factor for planning and implementation of business goals and for the development of economic activity in rural areas of Bulgaria. Rural areas in Bulgaria have the highest share of people at risk of poverty or social exclusion among EU countries. The risk of poverty has decreased over the last two years, but remains high and is above the EU-27 value. Macroeconomic stability and economic activity have contributed to a reduction in the share of people in poverty since 2014. However, regional imbalances are growing in rural areas of Bulgaria. Particularly worrying are the processes of depopulation in mountainous areas, where economic activity has fallen several times in the period 2014-2020 compared to the period 2000-2006. 


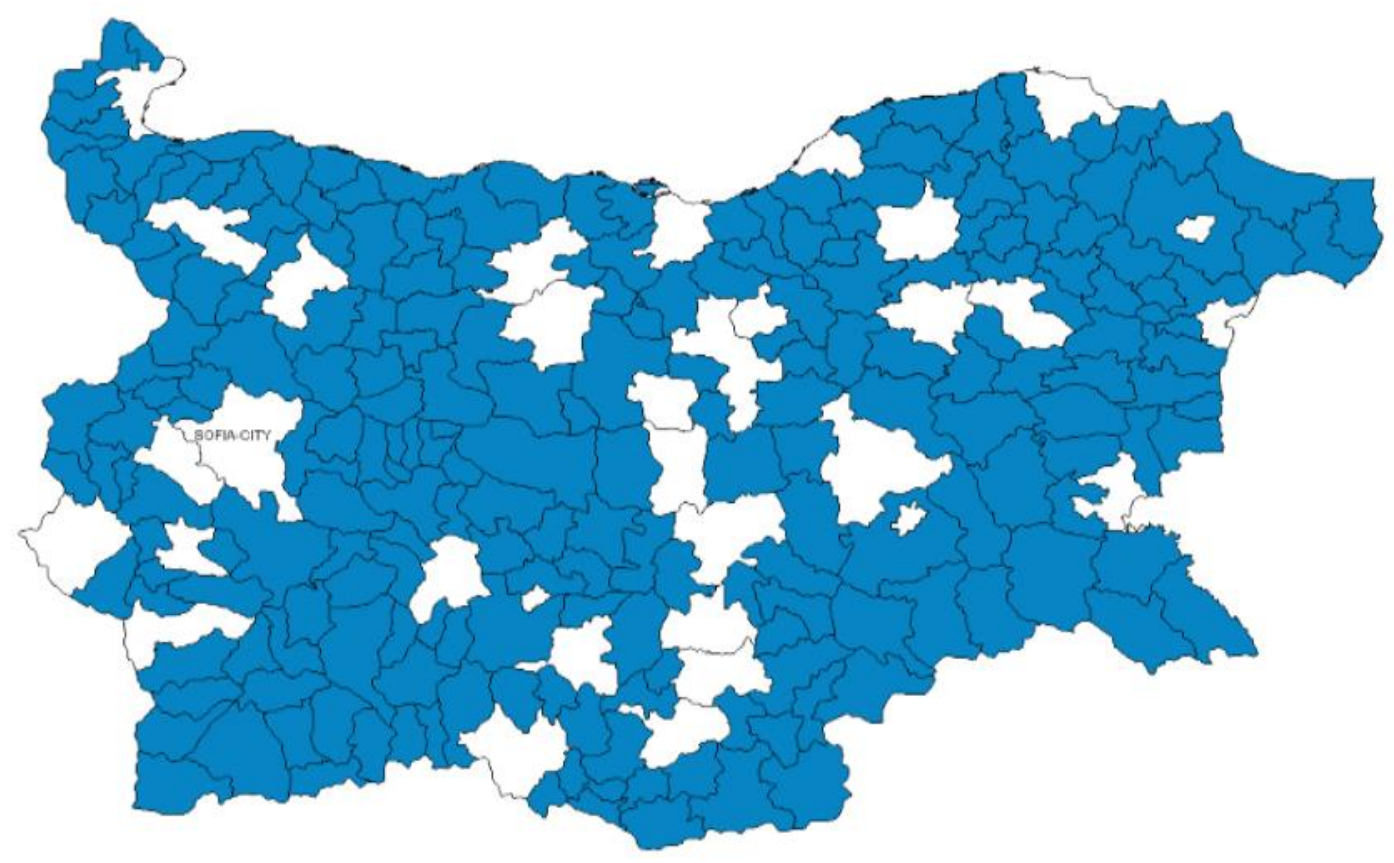

Fig 3. Rural areas in Bulgaria. Sources: NSI, Ministry of Agriculture and Food of Bulgaria

Small and medium-sized businesses in European rural areas are often defined as the backbone of the economy. Small and medium-sized enterprises are a key prerequisite for the existence of competition and functioning markets, and hence for the overall economic development of a country. It is no coincidence that EU business support policies focused precisely on supporting small and medium-sized enterprises to stimulate entrepreneurship and job creation, as well as a source of innovation. On the other hand, it is necessary to bring out the problems of rural areas in Europe and Bulgaria and in terms of the state of human resources. In practice, the demographic distribution in rural areas of the European Union is quite uneven. Thus, the uneven distribution of people at risk of poverty in the country shows income differentiation between rural and urban areas. It is important to note that the rural population has been declining sharply in recent years. Migration from rural to urban areas is undoubtedly among the main factors for rural depopulation. However, the influence tangibly subsides due to the severely exhausted migration and demographic potential of rural areas not only in Bulgaria but also in most of the developed countries. A few high waves of emigration to the cities in the late 50's and early 60's of the last century seriously undermine the potential of the rural population for simple reproduction and are a prelude to its replacement by deepening regressive type of reproduction This is a result of the lost economic profile of the villages in Bulgaria. In addition, internal and external migration, low birth rates, economic inequality in the development of regions, are factors that lead to a change in the number and structure of the rural population.

Tab 2. Gross domestic product per capita (in EUR). Source: Eurostat

\begin{tabular}{|c|c|c|c|c|c|c|c|c|c|c|}
\hline & Year & $\mathbf{2 0 0 8}$ & $\mathbf{2 0 0 9}$ & $\mathbf{2 0 1 0}$ & $\mathbf{2 0 1 1}$ & $\mathbf{2 0 1 2}$ & $\mathbf{2 0 1 3}$ & $\mathbf{2 0 1 5}$ & $\mathbf{2 0 1 6}$ & $\mathbf{2 0 1 8}$ \\
\hline $\begin{array}{c}\text { NUTS } \\
\mathbf{0}\end{array}$ & $\begin{array}{c}\text { EU-28. } \\
\text { GDP per } \\
\text { capital }\end{array}$ & 26130 & 24530 & 25500 & 26220 & 26680 & 26850 & 29140 & 29310 & 30960 \\
\hline $\begin{array}{c}\text { NUTS } \\
\mathbf{1}\end{array}$ & $\begin{array}{c}\text { Bulgaria } \\
\text { GDP per } \\
\text { capital }\end{array}$ & 4880 & 4930 & 5050 & 5610 & 5750 & 5770 & 6360 & 6820 & 7980 \\
\hline
\end{tabular}

Depopulation is mainly in villages that are in rural areas. Practically, in all municipalities in rural areas, settlements are grouped around the municipal center (usually a small town or a larger village). The institutions providing basic services are in the municipal center for the population educational, health, administrative, cultural and information centers, bank offices and shopping 
centers. The investments are mainly in the municipal center (the largest city in terms of population) and access and the quality of services is better than in the settlements outside the municipal one center in which the technical infrastructure is in poor condition, health and social service is of poor quality (Librecht I et al., 2004).

There is a significant influence on the formation of regional differences in birth rates. In Bulgaria, the main ethnic group is the Bulgarian, but there is also a Turkish ethnic group, which covers about $10 \%$ of the population, and a Roma, which is about $6 \%$. The other ethnic groups are less than $0.5 \%$. In practice, in recent years, there has been a decrease in the birth rate in Bulgaria. The Bulgarian group has lower indicators, a slowdown in the birth rate is also observed in the Turkish ethnic group, and in the Roma ethnic group, there is a higher birth rate, especially in the rural areas of Bulgaria. In recent years, the ethnic factor has begun to play an increasing role in the depopulation and migration of the population in Bulgaria. Thus, in the rural areas, there are specifics in different parts of the country. Where there are predominant Turkish and Roma ethnic groups, there is a slowdown in population decline, and in areas such as Kardzhali, it has a slight increase. At the same time, the reproduction of the rural population in the regions, municipalities and settlements with Bulgarians is becoming depopulated. The reasons are high mortality, aging, internal migration of young people to cities and deteriorating levels of local development. Thus, rural areas began to change their ethnic appearance, as well as socioeconomic structure.

\section{Structuring and features of zoning of rural areas}

In a sufficiently long period of time, rural population was crucial for the overall development of the country. From Liberation to the first years after World War II, Bulgaria has retained the agricultural character of economic development of Bulgaria as its dominant importance is agriculture population. During the same period, there was rapid growth of its cash which lasted until the mid-twentieth century. The total territory of the country is $110371 \mathrm{~km}^{2}$. The largest area is occupied by the intermediate municipalities $76.7\left(84654 \mathrm{~km}^{2}\right)$ Of the whole territory, the rural areas $22.1 \%\left(24387.9 \mathrm{~km}^{2}\right)$ and the city municipality - Sofia with $1.2 \%\left(1329.1 \mathrm{~km}^{2}\right)$. The population density indicator, which at the end of 2018 was $63.9 \mathrm{~d} / \mathrm{km}^{2}$, and in 2008, it was 68.4 people $/ \mathrm{km}^{2}$. In the regions according to the EU methodology, intermediate regions of 56.3 people $/ \mathrm{km}^{2}$, rural areas - $37.1 \%$, urban - Sofia is 999 people $/ \mathrm{km}^{2}$. Rural areas are predominant as a territory in Bulgaria and cover $84654 \mathrm{~km}^{2}$, the population density in them is on average 27.1 people $/ \mathrm{km}^{2}$ and is approximately three times lower than the national average (63.9 people $/ \mathrm{km}^{2}$ ). Having still a high proportion of the elderly population requires high social costs and limits opportunities for economic growth. It would be good if the population decline in small villages is due to the revival of small towns and large villages, which attract and retain the free labor force from small villages. The scope and quality of education in rural areas is still lower than in urban areas. The economic development of rural areas depends to a large extent on agriculture and the activities financed through the state budget. Diversifying the economy of small towns can be key to revitalizing rural areas and overcoming unequal development. Not only agriculture, but all other sectors can contribute to overcoming inequalities in rural development.

Following the accepted definition of rural areas (municipalities with a population of up to 30,000 people) and according to the European Typology of Municipalities, more than the rural population $(78.0 \%$ or $2,131,769)$ live in intermediate areas and $(22.0 \%$ or 600,117$)$ is concentrated in a typical rural. Practically, rural areas are areas that are not urbanized. They are low-density population and typically most of the land is occupied with agriculture. After the start of the accession of Bulgaria to the EU was to create strategies and modernization of existing contracts and accepting programs of territorial development. Policies pursued by the EU Rural Development aims to support a significant proportion of the rural population of the Community. Many of these areas are facing major social, economic, environmental and infrastructural challenges (Nikolov, G., Vasileva, E., 2017). Business activities and operating enterprises, employment in rural areas, agriculture and forestry, are still not sufficiently competitive. Increasing differences in population density for the country show a concentration of population 
in large cities and municipal centers at the expense of small settlements. For rural municipalities, population density decreases in proportion to population decline. Until 2011, Bulgaria and other rural areas in the EU were characterized by high waves of migration to cities and industrial concentrations, which are the main catalyst in the process of intensive depopulation of rural areas.

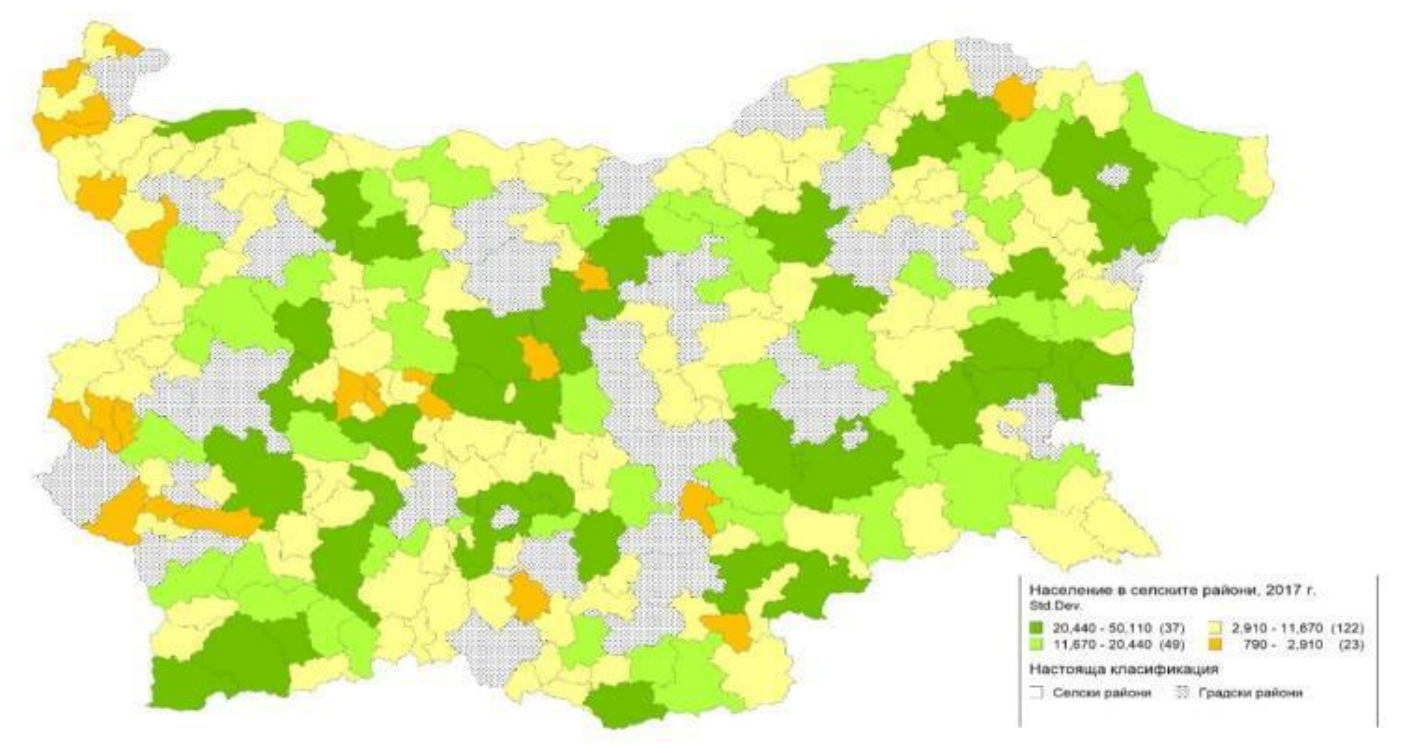

Fig 4. Population in rural areas according to the EU typology (2017). Source: NSI

Tab 3. Structure of migrants by areas of internal migration for period 1956-2020 (Bulgaria). Source: NSI (Bulgaria)

\begin{tabular}{|l|l|l|l|l|l|l|}
\hline \multirow{2}{*}{$\begin{array}{c}\text { Directions } \\
\text { of the inner } \\
\text { migration }\end{array}$} & \multicolumn{7}{|c|}{ Periods between censuses } \\
\cline { 2 - 7 } & $1956-1971$ & $1972-1983$ & $1984-1991$ & $1992-2001$ & $2001-2011$ & $2012-2020$ \\
\hline City - city & 16.6 & 30.2 & 38.3 & 42.5 & 46.5 & 57.4 \\
\hline Town - village & 8.1 & 9.9 & 13.3 & 23.4 & 26.1 & 18.4 \\
\hline Village - town & 44.7 & 42.7 & 34.3 & 22.0 & 16.6 & 17.2 \\
\hline Village - village & 30.6 & 17.2 & 14.1 & 12.1 & 10.8 & 7.0 \\
\hline Total & 100.0 & 100.0 & 100.0 & 100.0 & 100.0 & 100.0 \\
\hline
\end{tabular}

Based on expert assessment and public data of the national statistics of Bulgaria, it can be assumed that the rural municipalities in the country do not exceed 30 thousand inhabitants. Provided that each municipality consists of at least a few settlements, it is evident that in rural municipalities, the urbanized areas do not cover a large area. In this way, we can find that in rural areas, the main livelihood is related to agriculture and agricultural production. This frames the main problems facing the Bulgarian countryside and the rural areas in Europe in general, what path of development they choose. In practice, agricultural production is important for the development of the regions, but it does not have the necessary added value to be able to retain a larger population in these areas. The role of the agrarian inherited from the previous decades is also significant rural overcrowding leading to low productivity and hidden employment in agriculture. They contribute to the dissolution of the scissors between the conditions and the standard of living between villages and towns (Vidal C. et. Al. 2001).

In literature, the term "rural areas" is considered individually by given their specialization aimed at developing activities related to the agrarian economy. The formation of rural areas is carried out under the influence of certain factors: location, agro-climatic, ecological, socio-economic, geo demographic, policy formation, infrastructure and others. These areas are in a continuous process of change and development depending on their location, proximity to large social and economic center, metropolitan areas, availability of technical and social infrastructure and others (Lowe, P., et. Al 1995). In terms of terminology and the formation of "Rural areas", there 
are various explanations and opinions. We share the view that rural areas can be defined as those areas in which the agricultural sector (agricultural workers) occupy a relatively high share of the population and live in them and the rural way of life predominates or the main activity is agricultural. According to the latest typology of the EC for the regions, the only urban center is the capital Sofia. The number of municipalities defined as intermediate rural is 169 , intermediate urban is 25, and 63 municipalities fall into the typology of mostly rural. These areas are described as areas with less developed technical and social infrastructure, lack of capital, low labor productivity, deteriorating social services and a lower standard than the national average. The role of municipal center has been successfully implemented in each village or a small town in the administrative unit determined by regulations. I share the opinion of those authors who define rural areas as smaller administrative territorial units that are part of the regionalization of the country (Madzharova St. et. al., 2011).

However, on the other hand, there may be rural municipalities that cover significant areas and spaces. In practice, for rural areas, we can conclude that the population is mainly engaged in agricultural activities. This work is related to the climatic features of the regions and the available labor resources. Referring to an expert assessment, about $7.6 \%$ of the population in Bulgaria is engaged in typical agricultural activity. The problem, however, is that in this sector, we have an extremely low level of social security for those working in it. In Bulgarian agriculture, only 89,850 or $12 \%$ of the total number of employees are socially insured, it is assumed that 751,700 people are related to agricultural activity in the country, of which about $40 \%$ are employed full time $(343,100)$. This is one of the serious problems facing Bulgarian agriculture due to the lack of sustainable development of companies in it. This is the reason why in the period 2014-2018, in agriculture, there is a decline in economic activity. Their decrease is related to migration, and hence to the lack of investment interest in new production in a number of rural areas, and hence the deterioration of technical and social infrastructure in rural areas. In rural areas in our country, there are a number of socio-economic, demographic and other problems. The quality of life in them is still far from that in the cities. The existing irrational and poorly connected structure of the branches hinders the full use of available resources. Opportunities for income outside agriculture are limited. Homemade a holding has no commodity character and is developed mainly for the purpose of self-satisfaction. The access of people living in rural areas and especially in villages to education is limited and does not meet the needs of the local labor market. In practice, Bulgaria needs reforms in terms of implementing effective rural development policies. They are related to a change in tax policy and the imposition of a new model of regional rural development. Undoubtedly, we need to think about creating programs and projects that promote the development of local business and education of the rural population in order to build reliable human capital. (Wegener M., et. Al 2002). In Bulgaria, the rural areas have formed several heavily depopulated areas and these are the Northwestern area, Western border, Central Stara Planina and Fore-Balkans, SakarStrandzha region, Kraishteto and others. But on the other hand, these are territories in the zone of gravity of the Capital and the larger cities of Bulgaria. One can think of building villa zones and urbanized smart villages and smart regions where a new ecological way of life can take place. Of course, the current population in these areas is experiencing difficulties and is largely leaving these territories. The population in the villages in the rural areas is seriously decreasing and in the coming years, it is possible that they will be depopulated. The definition of the terms "rural" and "Rural areas" is crucial to detect regional differences in these concepts. Most economic studies prevails the understanding of rural areas in its geographic sense, connect more with certain territory, which has a diverse and dispersed business with clear predominance of primary economic activities. Thus, in practice, the typology and the specifics of rural areas often require careful analysis. This analysis is necessary to provide information about their territorial scope, socio-economic and demographic trends. Next to outline the opportunities for development of the villages from municipalities with different types of centers (city, village), as well as for the villages of the urban municipalities. The factors that determine the appearance and hence, are also important diversity in rural areas. Especially for the rural areas in Bulgaria, the prerequisites and conditions for development have an important role, as well as the obstacles that are overcome or create strong restrictive conditions (Madzharova St., et. Al 2013). It is quite logical the expectation that at the current rate of 
depopulation, many of the Bulgarian villages will be completely depopulated by 2050 not only in theory. Others probably will survive or even increase their population. The idea is to look for the spatial patterns in the picture of rural depopulation of municipal level in the future and thus to emerge the strongest rural areas at risk of terminal depopulation in the country.

\section{Connectivity and focus on European visions for rural development}

In the European Union for rural areas, adopted territorial units have a population density of people per square kilometer or share of agricultural employment equal to two times higher than the Community average for any year after 1985. Developments in socio-economic objectives of a particular EU country affects the overall development of rural regions. This threshold varies too widely, EU than 200 residents of Sweden to 10000 Italy or Germany. The European Commission in 1988 in his post as follows: "The future of rural society" provides a definition of rural areas are shaped by socio-economic and environmental structure. Those entities may include villages, towns, regional centers and other places. As a basis for the development of the typology of rural areas in the European Union, the one proposed by the Organization for economic cooperation and development (OECD) typology developed in the early 1990s. This typology is based on population density in the respective administrative units, and in 2009, the accessibility criterion was added (Lowe et al. 1995). Rural development is a vitally important policy area in the European Union. It works to improve aspects of the economic, environmental and social situation of the EU's rural areas. Rural regions cover $57 \%$ of the EU territory and $24 \%$ of the EU population. Together with intermediate regions, they comprise $91 \%$ of the EU territory and $59 \%$ of the total EU population. Across the EU, the dimensions of the rural-urban territorial vary from countries with an explicitly defined rural character (such as Ireland, Sweden, Finland, etc.) to Member States that tend to be more urbanised (such as the Benelux countries, Malta). The policy works essentially through seven-year rural development programmes (RDPs) - which operate at either national or regional level (Vard et al. 2005). These are funded from the EU budget, national/regional budgets and private sources. Rural Development policy targets rural areas as a whole, with a focus on ensuring the competitiveness of farms and forestry, delivering sustainable management of natural resources and climate action as well as create growth and jobs in rural areas. For some of the EU countries in their setting as rural areas, the main indicator is the number of inhabitants. The main criterion is the density population $\left(\mathrm{e} / \mathrm{km}^{2}\right)$, because $60 \%$ of the EU population live in those areas where geo-demographic factor negative natural growth or missing values are minimum. In 1996, the definition of rural areas as autonomous regions in need of emerging industries and activities other than the agricultural sector was adopted. Using the methodology of the OECD definition of rural areas based on population density and the share of the population in predominantly rural regions, a methodological framework is developed to define the problems of these regions (Nordregio 2004). In the Declaration of Cork for the first time, rural areas are defined as a source of public goods outside the sector of agricultural development, they are autonomous regions, which are not only a source of food resources and habitats forming its own appearance and development on the basis of a developed landscape, natural resources, cultural heritage, geo-demographic potential and others. A new element in rural development is to overcome the socio-economic differences. It appears as a new European base for development of this type of development. Parallel Assembly of the Council of Europe (PACE) adopted Recommendation №1296 / 1996. on the European Charter of rural areas. In this document, the rural area is defined as follows: "... internal and coastal areas, including villages and small towns where most of the land is used for: 1) agriculture, hunting, fishing and forestry; 2) economic and cultural activities of the population in these areas; 3) development of non-urbanized areas into areas for leisure or reserves; 4) for other needs such as residential areas.

Rural areas generally have an agricultural function which said social and economic influence in the development of the area. It is important to create acceptable living conditions in rural areas in terms of all economic, social, infrastructural, ecological and ethno-cultural aspects. Distinguished areas are located near large administrative center or near agglomerations to those located on the periphery of region (Schwarz, 2005). 
In areas for development, the specific way of life of local people and landscape protection must be considered. With this type of territories, it is needed for additional construction and development of infrastructure facilities of social and economic type. The transformation in agriculture and raising its competitiveness will be determined by diversifying economic activity in rural areas; the development of the service sector is a preservation of rural communities as a source of labor force and a prerequisite for the realization of those employed in agriculture (Guyyomond et al. 2008).

\section{Trends in the development of labor relations in rural areas}

The labor market is of key importance for the stability of the economy of the municipalities, for the development of the country, for the level of quality of life. Bulgaria's inclusion in the common European market still led to an intensification of trade in agricultural goods. It can be assumed that Agriculture ranks among the leading sectors of the national economy in terms of foreign exchange earnings, with several groups of products with divergent trends. Independence from the positive trends in agricultural contributions, all packages of its assortment structure, quantitative and qualitative parameters, outline problems with the stability of processes and competitiveness in international markets. This is because domestic production is characterized by shortcomings in four key factors: quantity of production, type, quality and price. The country is dominated by farms with low economic potential: with 1-8 economic units are about $90 \%$ (in the EU, this share is smaller by $1 / 3$ ), as they are mostly small (family) farms; over 40 economic units are less than $3 \%$ (in the EU, nearly 12\%). The average economic size of farms in the EU is almost three times higher than in our country (respectively 20.5 economic units in the EU and 7.9 economic units in Bulgaria). It can be said that this predetermines the lower economic potential of the Bulgarian agricultural sector compared to the EU average. The indicators characterizing the labor market can be related to the stage of economic development. The deteriorating demographic situation in rural areas is emerging as the most serious problem for their economic development (Patarchanov, P. 2009). One of the consequences of an aging population will be a change in the labor force, a change in the structure of the labor market, in social services and healthcare. A small number of elderly people will remain in the depopulated settlements, with limited mobility and financial independence, highly vulnerable and in need of health and social services. An increase in the relative share of the elderly is a prerequisite for increasing the risk of poverty in rural areas. The unemployment rate at the national level with that reported in rural municipalities is about twice as high, as the highest unemployment rate in rural municipalities was in $2013-20.9 \%$, and by the end of 2018 , it decreased up to $13 \%$.

Tab 4. Unemployment rates in Bulgaria. Source: NSI Bulgaria

\begin{tabular}{|c|c|c|c|}
\hline YEAR & $\begin{array}{c}\text { Odds of unemployment } \\
\text { for Bulgaria (\%) }\end{array}$ & $\begin{array}{c}\text { Unemployment rate } \\
\text { for urban } \\
\text { municipalities (\%) }\end{array}$ & $\begin{array}{c}\text { Unemployment rate for } \\
\text { rural municipalities } \\
(\%)\end{array}$ \\
\hline 2008 & 6.3 & 3.8 & 9.9 \\
\hline 2010 & 9.2 & 6.4 & 13.4 \\
\hline 2011 & 10.4 & 6.7 & 17.7 \\
\hline 2012 & 11.4 & 6.4 & 17.8 \\
\hline 2013 & 11.8 & 6.9 & 20.9 \\
\hline 2014 & 10.7 & 6.2 & 19.4 \\
\hline 2015 & 10.0 & 5.7 & 18.3 \\
\hline 2016 & 8.0 & 4.5 & 14.7 \\
\hline
\end{tabular}

The percentage of unemployed persons per 100 working-age population in rural areas exceeds that in urban areas. In rural municipalities per 100 working population there are from $8 \%$ to $17 \%$ unemployed, and in urban municipalities from $3 \%$ to $5 \%$. In 2013 , when the economic crisis peaked in the country, the highest levels of registered unemployed were reported compared to the working population in rural municipalities $17 \%$ and in 2018 , it was $9 \%$. 
The registered lowest levels of unemployed per 100 working age population in urban municipalities $-3 \%$. After 2013, there was a downward trend in the number of registered unemployed compared to the working population, reaching $9 \%$ in 2019 . The good results may also be due to the successful implementation measures under the rural development program (Petrov, 2014). The improved implementation of the measures under the Rural Development Program in the period 2014-2020 to create a decent national network of non-governmental branch organizations in rural areas, which will support labor relations and act to improve employment in the regions. The vision for rural development must contain the following elements. With regards to job creation and process management in rural areas, the implementation of targeted policies is needed, which must be restored in an attempt at publicity in the public sector and local business. This means that the horizontal objectives of the common agricultural economic policies are to mitigate the effects of climate change and adaptation, as well as on sustainable energy. It is necessary to think about promoting sustainable development and efficient management of natural resources such as water, soil and air. Also, the creation of local small and medium enterprises. In addition, to determine the level of diversification of the rural economy (change of the economic structure) and to determine the territorial one dimensions of sectoral policies in the forthcoming period 2021-2027. Because of the elaborated strategies, four axes which are directed towards improving the quality of life in rural areas are formed, creating new opportunities development activities outside the known traditional agricultural industries. Development rural and socio-economic status of the population is an important element by agrarian socio-economic policy. Micro enterprises in rural areas in 2008 are 72229 units, or $89 \%$ of all enterprises in rural areas, and in 2017 , have increased by 26,235 (36\% growth), or $92 \%$ of all enterprises in rural areas. For the period, there is an increase in micro enterprises. The increased number is due to newly established micro-enterprises in some of the municipalities. Medium-sized enterprises in 2008 are 820 units, or $1 \%$ of all enterprises in rural areas, and in 2017, there was a decrease of 167 units, or $0.6 \%$ of all enterprises in rural areas. The decline in medium-sized enterprises may also be due to the cessation or cessation of activities in some of the municipalities. Large enterprises in 2008 are 77 , or only $0.1 \%$ of all enterprises in rural areas, and in 2017 , they decreased by 10 pieces. Despite the small relative share, large enterprises also decreased for the period 2008-2017. The structure of SMEs in the period 2008-2017 evidenced some differences compared to 2008 in the direction of an increase in the share of micro-enterprises over $90 \%$ (both at national level and for rural areas), primarily at the expense of small and to a lesser extent medium and small enterprises. large enterprises. The distribution of enterprises by economic activities in the period 2008-2017 is maintained according to the sectors in which there is a large number of enterprises. As in 2008 and in 2017, most enterprises are in the sectors of trade and repair of motor vehicles and motorcycles, agriculture, forestry and fisheries and manufacturing, hotels and restaurants. For rural areas, more specific activities should be sought to develop the sectors (diversification of sectors). The problem with them is the deteriorating age structure, the outflow of young people, population decline and lack of human potential (Tsekov, 2015). In many of the smaller settlements, mostly elderly people over 65 years of age predominate, and in the urban areas (mainly in Sofia-city district) are concentrated mainly young people in active working age, where the human potential is many times higher than in rural areas. In some of the municipalities, the obstacle to economic development is the minority groups. While supporting the competitiveness of agriculture, it is expected to have a stronger link with the productivity of economic operators in the sector. At the same time, data on SME productivity are common to all sectors of the economy, which does not allow a link to be established with the productivity of SMEs in agriculture or food production. Regarding the weak connection with the municipal roads, the analysis of different classes of municipal roads revealed a moderate strength of the connection with the municipal roads of first class and almost zero connection with those of third class (Roques Alain, 2018).

In addition to the economic ones in the rural areas of Bulgaria, there are also groups of problems related to the water supply and water supply network. This is often the case in small settlements in most municipalities, where water infrastructure is depreciated, obsolete or undeveloped, as a result of which the use of drinking water for the population is limited. In terms of technical infrastructure, weaknesses and threats far outweigh strengths and capabilities. On 
the territory of Bulgaria, through cluster analysis, 4 types of rural municipalities are identified developed municipalities, catching up municipalities, developing municipalities and lagging behind. The analysis showed that municipalities in rural areas are not homogeneous, and there are significant differences between them in terms of economic activity, labor potential, labor productivity and income (Patarchanova, 2006). Targeted and cost-effective financing is needed to achieve economic cohesion between rural municipalities. It is necessary to study in detail the experience of other countries in the creation and practical implementation of policies for socio-economic stimulation of rural areas and for reducing disparities in the standard of living between villages and towns. Public services in mountain areas suffer from remoteness and the sparseness of the population. They are difficult to maintain because of the population decline, the trend towards centralisation in trade and services modernization, and sometimes new behavioural trends in mobility from users and consumers (Vidal et. al. 2001).

\section{Conclusion}

After 2020, there is a need to develop a mechanism for a closer link between the development of the agricultural and forestry sector, on the one hand, and villages as territorial units on the other. Improving the level of public services in rural areas. It is necessary for the rural areas in Bulgaria to become an active part of the European Network for Rural Development, participating with ideas, experience and exchange of good practices, as well as building the National Rural Network in Bulgaria. It is necessary to look for opportunities for rural development by improving the quality of life in them and imposing the achievements of innovation and new technologies in them. In addition, rural areas need a new programming model to focus on integrated funding of projects and programs that are both of public importance and to encourage local businesses to implement innovative projects and provide services. This is because rural areas as a whole lag behind in labor productivity and report higher levels of unemployment, which explains the lower purchasing power of the rural population than the average purchasing power index and lower income levels. New concepts have been outlined in rural policy, for example Smart villages with a focus on helping rural communities address problems related to developing new features and services improved, through digital, telecommunication technologies, innovation and better use of knowledge for the benefit of society and business. Digital technologies and innovations can support quality of life, higher living standards, public services for citizens, better use of resources, less impact on the environment and new opportunities for rural value chains in terms of products and improved processes. The integrated territorial approach allows further targeting of program resources to territorial needs and a combination of support from various sources and funds. The programs and policy instruments of convergence can encourage smart villages to build strategic transport and digital networks. Cohesion policy (2021-2027) emphasizes the need to apply an integrated territorial approach. Specific tools are integrated specialization strategies integrated Territorial Investment (ITI) and Community Led Local Development (CLLD). Territorial integration is based on integrated strategies use a functional approach that promotes territorial economic interaction between urban and rural areas. The exploitation of local potential corresponds to the goals: One Europe closer to citizens by promoting sustainable and integrated development of urban, rural and coastal areas and local initiatives and with a greener, low-carbon Europe, by promoting a clean and equitable energy transition, green and blue investments, circular economy, adjustment to the change of climate and risk prevention and management. In this sense, special significance acquires the development of a set of complex measures to stimulate the retention of young people in the villages through the preservation and expansion of access to public services and the introduction of tax and other financial incentives for new investment in the rural economy. 
[1] Bachev, H., Ivanov, B., Toteva D. \& Sokolova, E. (2017). Agrarian sustainability in Bulgaria - economic, socialand ecological aspects. Bulgarian Journal of Agricultural Science, 23(4), 519-525.

[2] Kopeva, D., Madjarova, Sv., Peneva, M. \& Harizanova, H. (2010). Review of the Transitional Restrictions Maintained by Bulgaria and Romania with Regard to the Acquisition of Agricultural Real Estate. Brussels: CEPS.

[3] Librecht, I., Tirry, D., Gallego, F. J., Van Orshoven, J., Vande Walle, S., Terres, J. M. (2004). A GIS approach to measure the rural character. Luxembourg: Office for Official Publications of the European Communities.

[4] Lowe, P., Murdoch, J. \& Ward, N. (1995). Networks in rural development beyond exogenous and endogenous models. In: van der Ploeg, J. D. \& van Dijk, G., eds., Beyond modernisation: The impact of endogenous rural development (pp. 87-105). Assen: Van Gorcum.

[5] Madzharova, St., Peneva, M. \& Patarchanova, E. (2011). Селски райони Sofia: Publishing House of University of National and World Economy.

[6] Marinov, P. (2018). Natural Resource Potential in the Rural Areas of the South Central Region. Plovdiv: Fast Print Books.

[7] Mountain Areas in Europe: Analysis of mountain areas in EU Member States, acceding and other European countries (2004). Stockholm: NORDREGIO. https://ec.europa.eu/regional_policy/sources/docgener/studies/pdf/montagne/mount1.pdf.

[8] Nikolov, G. \& Vasileva, E. (2018). Improvement of the Economic Development Policies in the Regions. Regional Economy and Sustainable Development, Conference Proceedings (pp. 78-85), Varna: University of Economics.

[9] Patarchanova, Em. (2007). The importance of small and medium enterprises for stable economy of the rural regions in Blagoevgrad district. Problems of Geography (0204-7209), vol. 3-4, 164-175.

[10] Patarchanov, P. (2009). Mountain regions economy - the sustainable area development challenges it faces. In Geography and Sustainable Development (367-374). Skipje: Macedonian Geographical Society.

[11] Petrov, K. (2007). Problematic aspects in the formation of regional policy of Bulgaria. Magazine Geopolitics issue 5, 25-28, https://geopolitica.eu/spisanie-geopolitika/922007/broi5-2007/1151-problemni-aspekti-pri-formirane-na-regionalnata-politika-nabalgariya.

[12] Reidsma, P., Tekelenburg, T., van den Berg, M. and Alkemade, R. (2006). Impacts of landuse change on biodiversity: an assessment of agricultural biodiversity in the European Union. Agriculture Ecosystems \& Environment, 114(1), 86-102.

[13] Schwarz, G. (2005). Classifying Rural and Urban Regions in the European Union: A Modified OECD Approach [Unpublished report].

[14] Tsekov, N. (2015). Demographic Outlook for the Smallest Rural Villages in Bulgaria. Население 3, 55-82.

[15] Vard, T., Willems, E., Lemmens, T. \& Peters, R. (2005). Use of the CORINE land cover to identify the rural character of communes and regions at EU level, In: Trends of some agrienvironmental indicators of the European Union. Luxembourg: Office for Official Publications of the European Communities.

[16] Vidal, C., Eiden, G. \& Hay, K. (2001). Agriculture as a Key Issue for Rural Development in the European Union. In Crivelli, P., ed., Conference on Agricultural and Environmental Statistical Applications in Rome (pp. 131-140). Rome: National Statistical Institute of Italy. 
[17] Wegener, M., Eskelinnen, H., Fürst, F., Schürmann, C. \& Spiekermann, K. (2002). Criteria for the Spatial Differentiation of the EU Territory: Geographical Position. Bonn: Bundesamt für Bauwesen und Raumordnung.

\section{Other sources}

[18] Guyyomond, H., Auberst, F., Levert, F. \& Schmit, B. (2008). Rural areas: Current situation and future challenges, unpublished presentation on the conference Europe's rural areas in act on: Facing the challenges of tomorrow 16-17 October, 2008, Limassol, Cypros.

[19] Rural Development Program. Agriculture and rural development. https://ec.europa.eu/agriculture/rural-development-2014-2020_en. 